\title{
Breve introducción a la Semiótica de protesta
}

\author{
Massimo LEONE *
}

Propuesto: 29 de marzo de 2012

Evaluado: 14 de abril de 2012

Aceptado: 23 de abril de 2012

(Abstracts y palabras clave al final del texto)

\section{INTRODUCCIÓN}

Un viento de protesta está sacudiendo el mundo entero. Es un viento que sopla desde lejos, pero últimamente se ha hecho impetuoso. Las elecciones presidenciales en Irán en 2009, los movimientos de revuelta en Túnez, Egipto, Siria, en todo el Medio Oriente; la ocupación simbólica de Wall Street; el $15 \mathrm{M}$ en España, con la Plaza de Sol repleta de manifestantes; las sublevaciones contra el TAV (Tren de Alta Velocidad - similar al AVE) Turín-Lyon en Italia, las luchas de los obreros y de los desempleados; los alborotos contra gobiernos políticos viejos e ineficaces. Parece que en un cierto punto de la historia el mundo se haya encendido, y siga iluminando con luz intermitente desde entonces: estallan fuegos de protesta, se difunden, devoran regímenes, gobiernos, leyes; algunos se propagan de una parte a otra del globo a través de la nueva chispa de Internet, otros se sosiegan y se extinguen.

El investigador puede, como cualquier otro, entusiasmarse frente a tanta energía humana, a tanto deseo de renovación, al espectáculo del motor de la historia que parece mágicamente arrancar y no pararse; el investigador puede apasionarse con todo esto, y quizás deba hacerlo. Pero antes que nada el investigador tiene que comprender y ayudar a comprender. ¿Por qué la protesta se desencadena en ciertas circunstancias y no en otras? ¿Qué mueve los individuos, los grupos, los pueblos a soñar un estado de cosas diferente, a enterarse de lo inadecuado de sus propias existencias, a producir lenguaje y acción para cambiarles las señas?

Éstas son preguntas que se pueden formular no sólo con respecto a la gran escala de los fenómenos planetarios, de Cuba al Tíbet, de Londres a la Liberia; al

\footnotetext{
* Una versión en italiano de este artículo ha sido publicada en $E / C$, la revista on-line de AISS (“Associazione Italiana di Studi Semiotici”), el 20 de noviembre de 2011; agradezco a Gianfranco Marrone por la hospitalidad; agradezco a Eva Navarro Martínez por haber editado la primera versión en español de este artículo.
} 
revés, éstas son preguntas que tocan la vida cotidiana de cualquiera, incluso los que creen vivir en un mundo acolchado, pacífico, sin roces.Estamos haciendo la cola en una oficina de correos y de repente alguien nos sobrepasa y se pone delante; ¿por qué en ciertas latitudes se llega a aceptar tal comportamiento, y por qué, al revés, en ciertas otras eso sería intolerable? ¿Qué es que hace surgir en algunos el aliciente de la protesta, y qué empuja, al revés, otros a callarse, soportar, aceptar? ¿Y cómo se construyen las modalidades de la protesta, según que normas, recurrencias, innovaciones?

Hay varias maneras de analizar la protesta. Los historiadores trataran de hallar y ordenar documentos que les ayuden a comprender cómo se ha llegado al punto de quiebra, y también los recorridos, siempre tortuosos, a través de los cuales la rebelión ha tomado cuerpo, se ha desarrollado en el tiempo y en el espacio, ha envuelto lideres de nombres memorables y gente común, ha tenido éxito en su deseo de cambiar el rostro de una sociedad, de un país, incluso de la humanidad entera; o, al revés, se ha enfrentado a obstáculos insuperables, ha conocido el repliegue, la humillación, la traición. El trabajo de los historiadores de la protesta es fundamental.

Pero igualmente esencial es el de los sociólogos: ¿cuáles son las condiciones sociales que determinan la agregación de individuos en grupos de protesta?; y además — pregunta esencial para este tipo de búsqueda - ¿cuál es la relación entre protesta y poder? ¿Quien protesta lo hace en nombre de qué valores, ideales, condicionamientos, y rebelándose contra qué yugos, abusos, constricciones? Y más (perspectiva psicológica): ¿cómo se vive una escena de protesta en el interior de las propias cogniciones, en el foro íntimo de las propias emociones? ¿Qué mecanismos del pensamiento y de la pasión empujan a un individuo a arrojarse contra la fuerza pública, y cuáles al revés a aceptar el orden preestablecido?

Todas estas perspectivas, y las preguntas que las conciernen, son importantes para investigar en profundidad el fenómeno de la protesta. Sin embargo, este artículo adopta un punto de vista diferente, no va enfocado hacía las condiciones históricas, las causas sociales, y las dinámicas psicológicas que caracterizan la protesta, más bien hacía la protesta como fenómeno de significación y comunicación: en el lenguaje de la protesta, o en la protesta como lenguaje. Este artículo por lo tanto se centrará en los signos, los discursos, los textos con los que la protesta toma cuerpo, sale del espacio interior de los individuos y se vuelve experiencia sensible, revistiéndose de palabras, sonidos, colores, formas, gestos. La manera en la que la protesta se hace sentido compartido: éste es el núcleo principal del artículo.

Sin embargo, también con respecto a este tema, las perspectivas desde las que se podrían estudiar los lenguajes de la protesta son múltiples: la lingüística, por ejemplo, podría proponer un análisis puntual de las expresiones verbales — desde las más llanas hasta las más coloridas, desde la sobada repetición de eslóganes usados a las invenciones de los poetas - con las que una protesta se manifiesta; los visual studies, por su parte, podrían ayudarnos a entender mejor cómo las imágenes acompañan la palabra para generar el sentido global de una revuelta, de una sublevación, de un tumulto; los estudios sobre los medios de comunicación de masas nos darían instrumentos útiles para entender cómo los medios de comunicación, los tradicionales, 
pero sobre todo los nuevos medios digitales, juegan un papel llave en el contagio de los fenómenos de protesta.

El artículo que se introduce aquí se nutre de todos estos saberes pero prefiere uno de ellos en particular, considerándolo capaz de aunar todos los otros favoreciendo el diálogo y unas felices contaminaciones: la semiótica. Disciplina de intereses muy diversos, y por lo tanto de definiciones mutables, se designa comúnmente como la ciencia que estudia los sistemas de significación y comunicación. Sin embargo, hay otra manera, más filosófica pero también más profunda, de definir la semiótica. La semiótica es la disciplina de la alternativa. Para que haya signos en el mundo, y entonces para que haya lenguaje que los produzca y los interprete, es necesario que exista la posibilidad de elegir. Un signo significa solamente en virtud del hecho de que podría no significar, o que podría significar algo distinto. Una bandera quemada durante un cortejo, por ejemplo, es un signo violento de protesta en cuanto que es posible una alternativa, la de quien, por ejemplo, protesta sin destruir los símbolos queridos en otros países y construyendo símbolos nuevos, proponiendo su sentido al espacio común y a la pasión colectiva.

Donde esta posibilidad de alternativa no exista, no hay tampoco signos, ni entonces lenguaje, y por lo tanto, en definitiva, no existe tampoco lo humano. Al revés, para la semiótica el hombre (y la mujer) son intrínsecamente libres de transformar cada aspecto de lo real en signo de otra cosa, en un proceso infinito que solo pueden paralizar las costumbres y las rutinas. A fin de cuentas, ésta no es más que una reelaboración de lo que Umberto Eco, fundador de la semiótica italiana, mantenía desde su Trattato di semiotica generale de 1975: la semiótica es la disciplina que estudia todo lo que puede ser utilizado para mentir. Donde no haya posibilidad de elegir entre la verdad y la mentira, entre lo real y su alternativa, la semiótica no tiene nada que hacer.

La hipótesis quizás más general de este artículo deriva de la definición misma de semiótica. Por un lado, parafraseando a Umberto Eco, se podría decir que la semiótica estudia todo lo que puede ser utilizado para protestar. El lenguaje de la protesta, es decir los modos en los que los hombres construyen su grito de dolor, desasosiego e indignación frente al statu quo, no tiene límites: cualquier cosa puede ser empleada de tal manera que signifique esta insatisfacción hacia lo real. Esto incluye las palabras del lenguaje verbal, naturalmente, pero también las expresiones del rostro, los gestos y las posturas del cuerpo, los movimientos de los individuos y de las masas, la relación con el espacio circundante, los sonidos, los colores, las formas, incluso el silencio.

Por otro lado, esta hipótesis se traduce en una afirmación más general, de carácter filosófico: no sólo todo puede volverse signo de protesta; sino que además, la capacidad de protestar es característica intrínseca de lo humano.

El hombre o la mujer que protestan, de hecho, lo hacen porque consiguen imaginar una realidad potencial alternativa respecto a la que ellos viven y soportan. Desfilan en manifestaciones, gritan eslóganes, pintan pancartas porque son capaces de soñar una realidad distinta, y los signos de su protesta no son más que un medio semiótico con el que esperan transformar el sueño presente en uno futuro real, y lo real presente en una pesadilla del pasado. Donde no haya capacidad de protesta, donde lo real se reciba y acepte con fatalismo marmóreo, donde no se consiga ni 
siquiera imaginar que las cosas podrían ser diferentes respecto a como son, se expresa una concepción de lo humano que está muy lejos de la de la modernidad, y que tal vez esté lejos también de lo humano. El hombre (y la mujer) incapaces de protesta son maquinas, piedras, seres inanimados. Si incluso la naturaleza a veces parece rebelarse, y de protesta parecen capaces muchas especies vivientes no humanas, el hombre o la mujer que no consigan protestar, y ni siquiera concebir la protesta, se degradan debajo del animal, de la planta, de la naturaleza. Renuncian, es decir - a consecuencia de una coerción paradójica que les inflige la cultura - a su propia naturaleza de humanos, la cual es - ésta es la hipótesis de este artículo - intrínsecamente libre, capaz de producir infinitas representaciones alternativas de lo real, de soñarlas todas, y de luchar para conseguir algunas.

\section{EL CAMPO SEMÁNTICO DE LA PROTESTA}

En primer lugar, la semiótica puede ser útil para una definición más precisa, y por tanto para una mejor inteligibilidad, del campo semántico del término 'protesta'. Con la advertencia general de que éste presenta variaciones a veces considerables no solamente en el pasaje de una lengua a otra, y por lo tanto de una cultura a otra, sino también en la diacronía, la semiótica puede sin embargo procurar elaborar un mapa de tales variaciones, y entonces construir un esquema de la articulación de este campo semántico sobre todo a través del acercamiento y la comparación con términos y campos semánticos limítrofes. Por ejemplo, qué diferencia hay entre la protesta, la queja, el disentimiento, la desaprobación, el descontento, la oposición, la reclamación, la recriminación, la reivindicación, el alboroto, la sublevación, la revuelta, la rebelión, el motín, la sedición, la sublevación, el tumulto, la insurrección, la manifestación, para citar solo algunos de los términos afines a 'protesta'? Trabajando en el marco de una lengua y de su cultura, pero posiblemente a través de comparaciones con otros idiomas y civilizaciones, la semiótica puede comprender la manera en la que un cierto grupo social, y la cultura que lo caracteriza, recortan el campo semántico de la protesta de modos más o menos sutiles y precisos.

Siguiendo el ejemplo de Algirdas J. Greimas ${ }^{1}$, un buen punto de partida para un análisis de este tipo son los diccionarios, puesto que las definiciones ofrecidas por los lexicógrafos procuran ofrecer una cartografía, en forma condensada, del modo en que un cierto campo semántico se articula en un determinado contexto lingüístico, cultural, e histórico ${ }^{2}$. Por ejemplo, el diccionario de la Real Academia Española en su última edición define el verbo protestar como 1) "declarar o proclamar un propósito"; 2) "confesar públicamente la fe y creencia que alguien profesa y en que desea vivir"; 3) "hacer el protesto de una letra de cambio"; 4) "dicho de una persona: expresar impetuosamente su queja o disconformidad"; 5) "aseverar con ahínco y con firmeza"; 6) "expresar la oposición a alguien o a algo". Solamente las definiciones números uno, dos, cuatro, cinco, y seis tocan la dimensión política de la protesta, $\mathrm{y}$

1 Se puede consultar todo el corpus de las búsquedas semánticas de este autor, a partir de Greimas, 1966.

2 Para un reciente análisis ejemplar de este tipo, véase Marrone, 2010. 
sugieren algunos de sus rasgos importantes: el tenor pasional de la protesta, su carácter antagonista, la necesidad de su manifestación, etc.

\section{TENSIONES SOCIOCULTURALES E IDEOLÓGICAS DEL CAMPO SEMÁNTICO}

Pero, aunque el análisis de las definiciones de diccionarios puede ser el punto de salida de la búsqueda semántica, no debe ser su punto de llegada. Lo que más importa no solamente para el semiótico, sino también para la demanda social de conocimiento, es el modo en el que tensiones y desarrollos socioculturales conducen a una rearticulación y por lo tanto a una redefinición del campo semántico de la protesta, hasta influir también en las futuras sistematizaciones de los lexicó-grafos. Por ejemplo, cuando algunos mass-media ingleses utilizan el termino 'tumulto' ['riot'] o 'revuelta' ['revolt'] para designar los fenómenos del verano londinense de 2011, mientras otros mass-media los definen con la palabra 'protesta' ['protest'], ellos manifiestan una oposición centrada en la diferente articulación semántica de los tres términos, diferencia que es utilizada para interpretar tales fenómenos según distintas ideologías: si, por un lado, términos como 'tumulto' o 'revuelta' evocan principalmente un escenario de sedición generalizada a la que no corresponde un objetivo político preciso y que da lugar a manifestaciones propensas a la violencia, una palabra como 'protesta' se refiere, al revés, a un escenario distinto, en el que la violencia generalmente es mantenida bajo control incluso con el fin de perseguir un objetivo político determinado (hasta el punto que cuando esto no ocurre se explicita hablando de 'violenta protesta', mientras tendría menor sentido una locución como 'violento tumulto' y aún menos una como 'violenta revolución').

Sin embargo, si es verdad que los diversos puntos de vista ideológicos utilizan la articulación del campo semántico de la protesta y de los términos afines para proponer una cierta interpretación de determinados fenómenos sociales, también es verdad que estas proposiciones pueden conducir a una rearticulación del mismo campo semántico de la protesta. Esta es la razón por la que los diccionarios y sus definiciones pueden ser solamente un punto de partida y no uno de llegada: a fuerza de definir como 'revueltas' unos fenómenos de protesta, o bien como 'protestas' unos fenómenos de revuelta, se acaba mutando el campo semántico, y entonces el sentido de ambos términos, una mutación de la que los mismos lexicógrafos deberán dar cuenta. El modo en el que la lengua perfila contemporáneamente el plano de la expresión verbal y el del contenido semántico de un cierto grupo social es permanentemente mudable, y a la semiótica atañe la tarea de describir tales cambios y los impulsos ideológicos que los sostienen, sin olvidar que su posición metalingüística no es inmune a ellos.

\section{LOS CUATRO NÚCLEOS SEMÁNTICOS DE LA PROTESTA}

Dos son, por lo tanto, las operaciones que la semiótica debe cumplir. En primer lugar, inspirándose también en las definiciones de diccionarios, poner orden en el 
campo semántico de la protesta y en los de términos afines, sabiendo bien que las cartografías semánticas pueden racionalizar sólo parcialmente el carácter a menudo ambiguo y huidizo de las lenguas naturales. Por ejemplo, adoptando el marco teorético y la metodología de la semántica estructural, se comprende que el lexema 'protesta' está sostenido por lo menos por cuatro núcleos semánticos fundamentales; tres de ellos se refieren a la estructura actancial de la protesta. El primero es el de la objetividad: se protesta en relación a un objeto preciso, nunca en abstracto; decir 'yo protesto' sin explicar con referencia a qué seria absurdo, o bien suscitaría hilaridad. El segundo es el del antagonismo: se protesta siempre contra alguien o algo; cierto es que se puede decir: 'yo protesto a favor del movimiento verde en Irán', pero se presupone que tal protesta es dirigida contra el régimen que oprime el movimiento. El tercero es el de la asimetría de las agentividades (Leone, 2009a): quien protesta siempre está dotado de menor capacidad de actuar, por lo menos en relación al objeto de la protesta, respecto a quien es su destinatario; normalmente no es un padre quien protesta contra el comportamiento del hijo, a lo más le amonesta, le reprocha, le reprende, etc.; al revés, es el hijo quien protesta contra el padre, porque es exactamente en la inferioridad de capacidad agentiva, y por tanto de poder, que se estriba la protesta; es verdad que puede darse una situación en la que el padre proteste contra el hijo, pero ella sería exactamente el síntoma de una inversión, o por lo menos de un reequilibrio, de la asimetría agentiva entre los dos. Finalmente, el cuarto núcleo semántico de la protesta no se refiere tanto a su estructura actancial-tipo cuanto a la comunicativa: quien protesta ciertamente puede hacerlo silenciosamente, por ejemplo callándose o absteniéndose de un determinado comportamiento, sin embargo el silencio y la abstención no serán otra cosa que una forma de manifestación: la protesta no puede no consistir en algún tipo de expresión, o para decirlo en los términos de la semiótica generativa, en algún género de débrayage. De hecho, el fin último de la protesta es exactamente esto: producir una manifestación de sentido que, en relación a un determinado objeto, conduzca al reequilibrio de la asimetría de agentividades entre quien protesta y su antagonista.

\section{EL RELLENO DE UN ESQUEMA SEMÁNTICO: CONFIRMACIONES Y SUBVERSIONES}

La segunda operación que la semiótica debe cumplir es estudiar el modo en el que este esquema semántico interactúa con signos, discursos, y textos que no siempre se limitan a manifestarlo, confirmando así las definiciones del diccionario, pero que a veces al revés lo contradicen, sometiendo a tensión el campo semántico de la protesta y los de términos afines bajo el impulso de instancias ideológicas particulares. Por ejemplo, es verdad que la protesta siempre tiene un objeto, pero es verdad también que movimientos como el de los 'Indignados' parecen someter a tensión tal núcleo semántico, produciendo una forma de protesta que a menudo es percibida como generalizada, incluso como desprovista de objeto. En segundo lugar, es verdad que la protesta siempre es contra alguien o algo, pero también que son cada vez más numerosas aquellas formas de protesta en las que el antagonista no está precisamente identi- 
ficado, sino que se trata de una instancia negativa abstracta o hasta vacía. En tercer lugar, es verdad que la protesta normalmente implica una asimetría de capacidad agentiva, pero también que no es nada infrecuente, en la Europa contemporánea, que se definan como 'protesta' las manifestaciones de una mayoría contra una minoría, por ejemplo las protestas anti-inmigrados que han caracterizado países como Grecia, Italia, o España ${ }^{3}$. En cuarto lugar, es verdad que la protesta conlleva siempre alguna forma de manifestación, pero mucho del debate contemporáneo sobre la protesta versa exactamente sobre las características que su expresión debería poseer: ¿puede una protesta silenciosa definirse protesta (y no simplemente el silencio como protesta, sino una protesta que no se sale del foro interior del individuo)?; y, una cuestión aún más espinosa: ¿hasta qué punto puede identificarse como manifestación de protesta una que no se limite a la adopción del lenguaje verbal, del icónico, del musical, etc., sino que adopte el ejercicio de la fuerza física, y por tanto la violencia, como su forma expresiva? (Innamorati y Rossi, 2004) ¿Actuar directamente sobre su propio antagonista para reducir físicamente su agentividad, como en las peleas entre manifestantes y policías, pertenece a las manifestaciones de protesta?

Las ideologías que caracterizan una sociedad, así como las retóricas que ellas adoptan, juegan a menudo con la consustancial ambigüedad del lenguaje con el fin de desplazar el confín entre áreas semánticas y con él la definición social de los fenómenos y de los acontecimientos, con consecuencias evidentes a nivel político. Una cosa es cualificar una protesta estudiantil como manifestación, otra cosa es caracterizarla como sublevación: en ambos casos, la respuesta cognitiva, emotiva, y pragmática a la vez de los ciudadanos y de las instituciones podrá ser completamente distinta. La semiótica debe entonces observar, describir, y analizar estos continuos intentos de redefinición semántica de la protesta, y puede hacerlo solo combinando el estudio de las definiciones estáticas propuestas por los diccionarios con el de su evolución, y el modo en que la protesta se encarna en diversos tipos de signos, discursos, y textos.

\section{LOS OBJETOS DE UNA SEMIÓTICA DE LA PROTESTA}

Una semiótica de la protesta, por lo tanto, tiene como objeto en primer lugar los mismos hechos sociales de protesta. Por un lado, ellos producen une serie muy amplia y variada de manifestaciones de sentido que la semiótica puede investigar recurriendo a toda la gama de sus instrumentos analíticos: eslóganes y comunicados ${ }^{4}$, posturas y movimientos a la vez individuales y colectivos ${ }^{5}$, modificaciones del cuerpo a través de

3 Sobre las protestas de algunos grupos fundamentalistas cristianos en los EE.UU., así como sobre la 'protesta contra la protesta', véase Davidescu, 2011. El sitio web Urban Semiotics [www.urbansemiotics.com] contiene a menudo artículos sobre protesta, aunque el nivel del análisis no siempre sea académico; también el sitio Guerrilla Semiotics [www.guerrillasemiotics.com].

4 Un primer intento de análisis, aunque caracterizado por una fuerte dimensión ideológica, se encuentra en Rossi-Landi, 1968.

5 Para una introducción a la semiótica de los desfiles: Marin, 1967; sobre el análisis tensivo de las multitudes: Leone, 2006; sobre praxis y protesta: Fontanille, 2008; sobre la semiótica de la muchedumbre en algunos fenómenos de protesta en Turquía: Tambar, 2009. 
vestidos $^{6}$, máscaras, pigmentos, $\mathrm{u}$ otros 7 , imágenes de varios $\operatorname{tipos}^{8}$, sonidos y ruidos (Lahusen, 1996; Marconi, 2006; Leone, 2012a), relaciones con el espacio (Lussault, 2012), la arquitectura (O'Carroll, 1987), y los objetos, construcción de nuevos artefactos (Zingale, 2005; Milev, 2011), destrucción de artefactos (Welch, 2000), performances, son solamente algunos de los elementos que se pueden inventariar en cualquier manifestación de protesta entre las que han caracterizado las calles y las plazas del planeta en los últimos años (Leone, 2012c). Por otro lado, a menudo son los mismos fenómenos de protesta, a partir de los que se establece una cierta relación de una colectividad con el espacio, las que se convierten en texto, matriz de regularidades que la semiótica puede sondear apelándose al marco metodológico de la antropo-etno, o sociosemiótica ${ }^{9}$.

En segundo lugar, una semiótica de la protesta no debe analizar solo los textos producidos por los fenómenos de protesta, o los fenómenos de protesta que se vuelven ellos mismos textos, para comprender la articulación y la evolución del imaginario de la protesta en un cierto contexto histórico y sociocultural. Ella debe analizar también el modo en el que el texto de la protesta se hace objeto de meta-discursos y metalenguajes que, a través de medios diferentes, contribuyen a una continua redefinición del sentido de la protesta, obedeciendo a ideologías y retóricas más o menos explicitas ${ }^{10}$. Al final, no es sólo la protesta como relato de una relación actancial lo que interesa la semiótica, sino también el relato de la protesta que incesantemente es configurado y reconfigurado a través de reportajes periodísticos, comentarios políticos, representaciones cinematográficas, conmemoraciones públicas (De Maria, 2011), social networks, ${ }^{11}$ etc.

\section{EL HORIZONTE DE LA BÚSQUEDA.}

En el espacio concedido a este artículo se ha podido presentar con rasgos bastante generales el esquema heurístico que mi investigación sobre la semiótica de la protesta tiene la intención de seguir. El objetivo final de este recorrido puede ser

6 Sobre el uso de vestidos y más en general de la moda como forma de protesta: Sellerberg, 2005: 46, que a su vez reproduce la tipología de cinco 'estilos rebeldes' (imitación, dandismo, desamparo, barbarismo, y puritanismo) elaborada por Klapp, 1969; también en Emberley, 1987; sobre desnudez y protesta: Velasco Gutiérrez, 2006.

7 Por ejemplo el ayuno, sobre el que hay una bibliografía muy abundante. Sobre el reciente uso del ayuno como manifestación de protesta en la India: Shivakumar, 2011.

8 Por ejemplo, sobre el uso de la estética futurista por los manifiestos de protesta de los años 60: Fabbri, 2009, que cita a su vez Bartram, 2005 (Köppel-Yang, 2003 sobre la guerrilla semiótica de la vanguardia china); sobre la semiótica de las pintadas como forma de protesta: Leone, 2011.

9 Para un marco teórico general se puede consultar Marrone, 2001 y Leccardi, 2009 para un ejemplo de análisis etno-semiótico de la protesta.

10 Ejemplo de este punto de vista es la controversia entre, por un lado, Paolo Fabbri y Tiziana Migliore y, por el otro, Stefano Traini, a propósito del análisis semiótico de las ideologías con las que los medios de comunicación utilizan imágenes de protesta (¿o subversión?), en particular las de manifestantes armados durante las peleas con la policía del 14 de mayo de 1977 ( Fabbri y Migliore, 2010a; Traini, 2010; Fabbri y Migliore, 2010b). Al tema de la protesta se dedican muchos esbozos de análisis en DIS.AMB.IGUANDO, el blog de Giovanna Cosenza (www.giovannacosenza.wordpress.com) y Cosenza, 2007.

11 A fenómenos de protesta se dedican muchos de los artículos reunidos en Bigi y Codeluppi, 2011; Salerno, 2011 y Sebastio, 2011 y también Montanari, 2011. 
identificado en la inspiración conceptual ofrecida por la misma etimología de la palabra 'protesta' ['pro-testis'], que en muchísimas lenguas se refiere no solamente a la dinámica del manifestar, del poner delante a- y a favor de- alguien ['pro'], sino también a la textualidad ['testis'], concebida a la vez como dimensión social de la producción de signos (la textura del sentido) y como dimensión de su recepción social (el sentido de la atestación).

Comprender los modos en los que individuos y grupos actualmente construyen los textos de la protesta y en los que tales textos se vuelven en testimonio más o menos eficaz parece una tarea imprescindible para una semiótica que desee estar cada vez más en el centro de la sociedad contemporánea y de las apremiantes peticiones de conocimiento que ella produce.

Protesto, ergo sum, se podría decir, pero sólo a condición de que se conciba la protesta no como adhesión mecánica a la moda de la rebelión. El hombre o la mujer que gritan eslóganes sin entender verdaderamente sus raíces y su alcance, que dicen "no" sin construir un "si", que rechazan lo real sin ser capaces de soñar alternativas potenciales; pues bien, estos hombres y estas mujeres también son esclavos de la rutina, de la costumbre, de un gesto automático donde se pierde el gusto de la innovación que caracteriza lo humano. Existe de hecho una protesta contra la protesta: el movimiento de quien no se reconoce en la moda de la rebelión y se subleva, a su manera, para que se llegue a construir y compartir un nuevo lenguaje del sueño.

Tampoco "protesto ergo sum" tiene que significar que quien no protesta es necesariamente inhumano, maquina, piedra sin sueño y sin abertura al cambio. Hay circunstancias en las que manifestar el sobresalto por el desasosiego, por pequeño que sea, conduce a sufrimientos indecibles para si mismo y para sus seres queridos, y puede que incluso a la muerte. Los que no protestan no siempre no son capaces de imaginar una realidad alternativa respecto a la terrible que están soportando. Los sistemas sociales que constriñen los hombres y las mujeres en estas condiciones, en esta incapacidad de protestar, son condenables exactamente por esta razón: arrancan la voz a sus súbditos, y sobre todo frustran su humanidad, la intrínseca capacidad de volver lo real en matriz de signos infinitos, de sueños infinitos. El objetivo de una semiótica de la protesta, más allá de sus ambiciones teóricas, es por lo tanto también esto: comprender el pasaje desde la posibilidad de la protesta hasta su imposibilidad, desde la capacidad de dar voz al sueño a su mutilación, entender donde anide, en qué recoveco del lenguaje de la protesta, el interruptor que los regímenes bajan con mano brutal para destruir toda potencialidad.

Sin embargo, y simétricamente, una semiótica de la protesta persigue también vislumbrar nuevas posibilidades y nuevas practicas de protesta. Incluso donde la represión parezca total, hasta en la ceniza donde toda chispa de la imaginación parezca apagada, surgen, como mágicamente, nuevas llamitas, y se manifiestan a menudo en la poesía que inventa nuevos modos - al principio sutiles, casi imperceptibles - para expresar la impaciencia y el sueño. Divisar estas llamitas, mirarlas mientras se nutren de ellas mismas, despiden despacito chispas, se propagan, se vuelven fuego ardiente, hasta el estallido de incendios que todo devoran - los abusos, las injusticias, las tiranías - es el espectáculo lo más extraordinario que lo humano pueda abastecer, un tributo a la naturaleza intrínsecamente libre de los hom- 
bres y de las mujeres, a su innata capacidad de representar y representarse las alternativas de la realidad, significar su sueño, comunicarlo a los otros, y transformarlo en una nueva realidad compartida.

\section{REFERENCIAS BIBLIOGRÁFICAS}

Bigi, Nicola y Codeluppi, Elena, eds (2011): "Viaggio nei social network". Número monográfico de E/C, revista de la AISS, “Associazione Italiana di Studi Semiotici”. 9.

Cosenza, Giovanna (2007): Semiotica della comunicazione politica. Roma: Carocci.

DAvidescu, Gordon. (2011): "Protesting Westboro Baptist Church Protesters at a Protest" [online]. Urban Semiotics, 27 de junio de 2011. Disponible en el sitio web www.urbansemiotic.com/2011/06/27/protesting-westboro-baptist-church-protesters-at-a-protest/; (ultimo acceso 19 de noviembre de 2011).

De Maria, Cristina, (2012): "Liturgies of Memory. When Remembering Becomes Denunciation: the Case of Las Madres de la Plaza de Mayo". En: Leone, Massimo, ed. “The Semiotics of Worship". Número monográfico de Lexia, nueva serie. 11-12. Roma: Aracne.(en prensa).

EMBERley, Julia, (1987): "The Fashion Apparatus and the Deconstruction of Postmodern Subjectivity". Canadian Journal of Political and Social Theory/Revue canadienne de théorie politique et sociale. 11, 1-2: 39-89.

FABBri, Paolo, (2009): "Presentazione". En: Bove, Giovanni. Scrivere futurista. La rivoluzione tipografica tra scrittura e immagine. Roma: Edizioni Nuova Cultura,. Disponible online en el sitio web www.paolofabbri.it/articoli/bove.html. (Último acceso el 19 de noviembre de 2011).

FABBri, Paolo y Migliore, Tiziana (2011): "14 maggio 1977. La sovversione nel mirino" [online]. E/C, revista de la AISS, Associazione Italiana di Studi Semiotici, marzo de 2011a. Disponible en el sitio web www.ec-aiss.it/. (Último acceso el 19 de noviembre de 2011).

- (2011): "Col senno di poi. Intorno a "14 maggio 1977. La sovversione nel mirino"” [online]. E/C, revista de la AISS, Associazione Italiana di Studi Semiotici, 5 de noviembre de 2011b. Disponible en el sitio web www.ec-aiss.it/. (Último acceso el 19 de noviembre de 2011).

Fontanille, Jacques (2008): Pratiques sémiotiques. Paris: Presses Universitaires de France.

Greimas, Algirdas Julien 1966): Sémantique structurale: Recherche de Méthode. Paris: Larousse, 1966.

InNAMORATI, Marco y Rossi, Alessandro (2004): La rete dell'odio. Analisi strategica, semiotica e psicologica dell'integralismo, fondamentalismo e razzismo su Internet. Roma: V. Casini.

KLAPP, Orrin Edgar (1969): Symbolic Leaders: Public Dramas and Public Men. Chicago: Aldine.

Köppel-YAng, Martina (2003):. Semiotic Warfare: the Chinese Avant-Garde, 1979-1989. A Semiotic Analysis. Hong Kong: Timezone 8.

Lahusen, Christian (1996): The Rhetoric of Moral Protest: Public Campaign, Celebrity Endorsement, and Political Mobilization. Berlino e New York: de Gruyter.

LECCARDI, Ilaria (2009): "Semiotica ed indagine etnografica. Discorso politico e pratiche di autogestione all'interno della fabbrica argentina Zanon" [online]. Ocula, 10, diciembre de 2009. Disponible en el sitio web www.ocula.it/rivista.php?id=20. (Último acceso el 19 de noviembre de 2011).

Leeuwen, Theo, ed. Critical Analysis of Musical Discourse. Número monográfico de Critical Discourse Studies. New York y Londres: Taylor \& Francis, 2012a: en prensa. 
LEONE, Massimo (2011): "Rappresentare la moltitudine. Qualche riflessione semiotica" [online]. E/C, revista de la AISS, , Associazione Italiana di Studi Semiotici, 19, 2006. Disponible en el sitio web www.e-aiss.it/archivio/tematico/arte/arti_figurative.php. (Último acceso el 19 de noviembre de 2011).

ed.(2009): “Attanti, attori, agenti -Il senso dell'azione e l'azione del senso; dalle teorie ai territory/Actants, Actors, Agents- The Meaning of Action and the Action of Meaning; from Theories to Territories". Número monográfico de Lexia, nueva serie, 3 4, junio. Roma: Aracne, 2009a.

(2009): “Le Parkour sémiotique - Pratiche urbane di invenzione della naturalità". En Bonadei, Rossana, ed. NaturaleArtificiale. Il palinsesto Urbano. Bergamo: P. Lubrina, 2009b: 147-168.

(2010): "Semiotica del parkour". En Cervelli, Pierluigi, Romei, Leonardo, y SedDA, Franciscu, eds. Semiotica dello sport. Roma: Edizioni Nuova Cultura, 2010: 208-224.

(2011): "Il graffito di Dio" [online]. E/C, revista de la AISS, Associazione Italiana di Studi Semiotic”, 5 de febrero de 2011. Disponible en el sitio web www.ec-aiss.it. (Último acceso el 19 de noviembre de 2011).

(2012): "My schoolmate - Protest music in present-day Iran". En VAN.

(2012) “The Semiotics of Parkour". Kodikas - Ars Semeiotica. Tubinga: Narr 2012b, en prensa.

(2012): “Semiotica della Protesta/Semiotics of Protest”. Número monográfico de Lexia, nueva serie. Roma: Aracne, 2012c.

- ed. Immaginario/Imaginary. Número monográfico de Lexia, nueva serie, 7-8, junio. Roma: Aracne, 2010: 243-254.

LithGow, Michael (2010): “The Semiotics of Protest: Ethnographic Violence and Squatting in Parking Lots during the 2010 Olympic Games" [online]. Art Threat: Culture + Politics, 25 de febrero de 2010. Disponible en el sitio web

www.artthreat.net/2010/02/vivo-newscast-2-2/. (Último acceso el 19 de noviembre de 2011).

Lussault, Michel (2011): "Bienvenue dans la nouvelle lutte des places!" [online]. Raison Publique, 3 de enero de 2012. Disponible en el sitio web http://www.raisonpublique.fr/article491.html. (Último acceso el 19 de noviembre de 2011).

Manetti, Giovanni, Bertetti, Paolo, y Prato, Alessandro (2005): Guerre di segni. Semiotica delle situazioni conflittuali. Acta del XXX Congreso de la AISS, "Associazione Italiana di Studi Semiotici”. Torino: Centro Scientifico Editore, 2005.

MARCONI, Luca (2011): “TRESPASSER or PasserBy? Per un analisi semiotica del Progressive Rock" [online]. Trans: Revista transcultural de música, 10. Disponible al sitio web www.sibetrans.com/trans/a155/trespasser-or-passerby-per-un-analisi-semiotica-del-progressive-rock. (Último acceso el 19 de noviembre de 2011).

MARIN, Louis (1967): "Notes on a Semiotic Approach to Parade, Cortege, and Procession". En Falassi, Alessandro, ed. Time Out of Time - Essays on the Festival. Albuquerque: University of New Mexico Press, pp. 220-230.

Marrone, Gianfranco (2001): Corpi sociali: Processi comunicativi e semiotica del testo. Torino: Einaudi.

- (2010): “Semantica della Natura. Un campo dei miracoli”. En Milev, Yana. "Emergency Design: New Semiotic Orders of Urban Survival". En GLEINIGER, Andrea, HiLbeCK, Angelika, y ScotT, Jill, eds. Transdiscourse 1: Mediated Environments. Vienna: Springer: $145-160$.

MONTANARI, Federico (2011): “Il limbo e il furore. I portali della rivolta [online]”. En Parlare di Oggi. Número monográfico de Alfabeta 2, 10 de junio de 2011. Disponible en el sitio web http://www.ec-aiss.it. (Último acceso el 19 de noviembre de 2011). 
O'Carroll, John (1987): “The Semiotics of Protest in Canberra”. Australian Journal of Cultural Studies. Vol. 4, n. 2, 1987: 153-161.

Rossi-Landi, Ferruccio (1968): Il linguaggio come lavoro e come mercato. Milan: Bompiani.

SALERNO, Davide (2011): “'Baseej have guns we have brains'. L'onda verde iraniana su Twitter". En Bigi, Nicola y CoDELuPPI, Elena, eds. "Viaggio nei social network". Número monográfico de "E/C", rivista online dell'Associazione Italiana di Studi Semiotici (AISS), 9. Palermo: E/C, 2011: 39-50. Disponible en el sitio web www.ec-aiss.it/monografici/9_social_network.php. (Último acceso el 19 de noviembre de 2011).

Sebastio, Marco. (2011): "Guerrilla semiotica 2.0. Le nuove forme civiche della contestazione sociale tra archetipi, marketing e social network". En Bigi, Nicola y Codeluppi, Elena, eds. "Viaggio nei social network". Número monográfico de $E / C$, revista de la AISS, Associazione Italiana di Studi Semiotici. 9. Palermo: E/C, 2011: pp. 51-62. Disponible en el sitio web www.ec-aiss.it/monografici/9_social_network.php. (Último acceso el 19 de noviembre de 2011).

Sellerberg, Ann-Mari (2005): "La moda". En Baldini, Massimo, Semiotica della moda. Roma: Luiss University Press; Armando: 35-50.

ShIVAKumar, Hamsini (2011): "Signs of Discontent" [online]. Semionaut: Signifying Everything, 29 de julio de 2011. Disponible en el sitio web www.semionaut.net/signs-ofdiscontent/. (Último acceso el 19 de noviembre 2011).

TAMBar, Kabir (2009): "Secular Populism and the Semiotics of the Crowd in Turkey". Public Culture. 21, 3: 517-537.

Traini, Stefano (2011): "L'analisi di una foto e il metodo semiotico. A proposito del saggio di Paolo Fabbri e Tiziana Migliore sulla foto '14 maggio 1977'" [online]. E/C, revista de la AISS, Associazione Italiana di Studi Semiotici, 25 de octubre de 2011. Disponible en el sitio web www.ec-aiss.it. (Último acceso el 19 de noviembre de 2011).

Velasco Gutiérrez, Pablo (2011): "El cuerpo desnudo y la semiosfera de la protesta en México" [online]. Entretextos: Revista Electrónica Semestral de Estudios Semióticos de la Cultura, 7 (mayo). Disponible en el sitio web

www.ugr.es/ mcaceres/Entretextos/entre7/velasco.htm. (Último acceso el 19 de noviembre de 2011).

Welch, Michael (2000): Flag Burning: Moral Panic and the Criminalization of Protest. New York: Aldine de Gruyter.

Zingale, Salvatore, ed (2005): La semiotica e le arti utili: in undici dialoghi. Bergamo: Moretti-Honegger. 


\title{
RESUMEN
}

El artículo se plantea el objetivo de utilizar las teorías y los métodos más avanzados de la semiótica de la cultura al fin de desarrollar una mejor comprensión de un fenómeno comunicativo central de las sociedades contemporáneas: la protesta. El tópico de la protesta no será analizado desde el punto de vista de sus causas y motivaciones histórico-sociales, mas desde el punto de vista de su lenguaje: ¿Cuáles fenómenos de sentido y comunicación designamos con el término "protesta"? ¿Cuáles condiciones contextuales deben verificarse para que una protesta tenga lugar? ¿Cómo se articulan los lenguajes, los discursos, los textos, y los signos de la protesta? ¿Por medio de qué códigos? ¿O bien, contraviniendo a qué códigos? ¿Cómo se lee e interpreta el sentido de una protesta según su público, y con qué efectos pragmáticos? Y más: ¿existen unas 'culturas de la protesta', que cambian según los periodos históricos y las áreas socio-culturales, y cómo interaccionan con la evolución de los medios de comunicación, y en particular con el origen y el desarrollo de los medios digitales? En detalle, cómo se pueden describir las dinámicas comunicativas que caracterizan la protesta en su relación con las redes sociales? Más en general: ¿dentro de qué marco teórico se puede definir la relación entre sentido, consenso, y disenso?

Palabras clave: protesta, movimientos sociales, semiótica

\begin{abstract}
The article proposes the objective of using the theories and the most up-to-date methods of Semiotics of Culture in order to develop a better understanding of a central communicative phenomenon of contemporary societies: the protest. The topic of the protest will be not discussed from the point of view of its causes and social-historical motivations, but from the point of view of its language: what meaning and which communication phenomena are designated with the term "protest"? What contextual conditions must be verified in order that a protest takes place? How are languages, discourses, texts, and the signs of protest articulated? Through what codes? Or against to what codes? How could be read and interpreted the meaning of a protest according to an audience, and with what pragmatic effects? And more: do there are a few 'protest cultures', affected by the changes according to historical periods and socio-cultural areas, and how they interact with the evolution of and in particular with the origin and development of digital media? In detail, how you can describe communication dynamics that characterize the protest in its relationship with the social networks? More in general: in which theoretical framework may be defined the relationship between sense, consensus, and dissent?
\end{abstract}

Key words: protest, social movements, semiotics.

\section{RÉSUMÉ}

L'article se pose l'objectif d'utiliser les théories et les méthodes plus récentes de la Sémiotique de la Culture afin de développer une meilleure compréhension d'un phénomène de communication central dans les sociétés contemporaines : la protestation. Le thème de ne sera pas discuté du point de vue de ses causes et ses motivations historiques-sociales, mais du point de vue de la langue, le sens et les phénomènes de la communication désignées par le terme «protestation»? Quelles conditions contextuelles doivent être vérifiées pour que une manifestation aurait-elle lieu ? Comment les langues, discours, textes et les signes de protestation se formulent ? Grâce à quels codes ? Soit, contrairement à quels codes ? Comment se lit et se interprète le sens d'une protestation selon l'auditoire et avec quels effets pragmatiques? Et en plus : il y a quelques «cultures de protestation», qui change selon les périodes historiques et régions socio-économiques-culturelles, et comment ils interagissent avec l'évolution et, en particulier avec l'origine et le développement des médias digitaux? En détail, comment peut-on décrire la dynamique de communication que caractérise la protestation dans sa relation avec les réseaux sociaux ? Plus en général : dans quel cadre théorique peut on définir la relation entre sens, consensus et dissidence?

Mots clé: protestation, mouvements sociaux, sémiotique. 